\title{
COPPER AND COBALT UPTAKE BY METALLOPHYTES FROM ZAIIRE
}

\author{
by R. S. MORRISON*, R. R. BROOKS*, R. D. REEVES* and F. MALAISSE**
}

\author{
Key words
}

Aeolanthus Cobalt uptake Copper uptake Haumaniastrum

\section{Summary}

Pot trials were carried out on plants of Haumaniastrum katangense, Haumaniastrum robertii and Aeolanthus biformifolius. These metallophytes from Zaïre were grown in substrates containing from $0-10,000 \mu \mathrm{g} / \mathrm{g}(0-1 \%)$ copper or cobalt. The tolerance of each species was determined and for cobalt was highest in $H$. robertii $(4000 \mu \mathrm{g} / \mathrm{g})$ and for copper was highest in Aeolanthus biformifolius $(9000 \mu \mathrm{g} / \mathrm{g})$. Discontinuities in the plant-soil curves for each element indicate an exclusion mechanism operating for all three species at lower concentrations of the element in the soil. All species would grow in soils containing only traces of cobalt or copper and this indicated that uptake of heavy metals was not linked to a physiological requirement for either element. The plant-soil relationship for cobalt $(P<0.001)$ was sufficiently good for all three species for them to be useful in biogeochemical prospecting for this element.

\section{Introduction}

The flora of the 'Copper Belt' of Central Africa is characterised by a number of endemic taxa adapted to high copper and cobalt concentrations (typically $4 \%$ and $1 \%$ respectively) in the soil overlying this region which extends from Southern Shaba Province Zaïre to Northern Zambia. Some of these plants such as Becium homblei ${ }^{4}$, Haumaniastrum rober$t i i^{2}$ and $H$. katangense ${ }^{3}$ are said to be indicative of copper deposits though not accumulating significant concentrations of this element. Recently it has been shown ${ }^{2}$ that in fact $H$. robertii has not only an unusual tolerance to copper but is able to accumulate extraordinarily high concentrations of cobalt (up to $1 \%$ in the dried vegetation). Unusually high concentrations of copper (up to $0.26 \%$ in dried leaves) have also been reported for Aeolanthus biformifolius ${ }^{5}$.

Uptake of copper and/or cobalt by plants is of importance in two scientific fields. If there is a good correlation between cobalt or copper concentrations in plants and in the substrate, the plant species can be used for biogeochemical prospecting ${ }^{1}$. Secondly, a study

\footnotetext{
Present addresses:

* Department of Chemistry, Biochemistry and Biophysics, Massey University, Palmerston North, New Zealand, and

** Laboratoire de Botanique et Écologie, Université Nationale du Zaire Lubumbashi, Zaüre.
} 
of the uptake can lead to conclusions concerning the mechanisms of elemental accumulation, a factor of interest for phytochemistry and allied fields.

In the present study, we have carried out pot trials on three metaltolerant taxa from Zaïre and measured their uptake of copper and cobalt and tolerance to these two elements. The results of this survey are reported here.

\section{Materials and methods}

Species studied were: Aeolanthus biformifolius De Wild, Haumaniastrum katangense (S. Moore) Duvign. et Plancke, and Haumaniastrum robertii (Robyns) Duvign. et Plancke.

A series of pots were prepared, each containing about $200 \mathrm{~g}$ of sterilized soil containing varying concentrations of cobalt and copper added as nitrates. Concentrations ranged from almost zero up to $10,000 \mu \mathrm{g} / \mathrm{g}(1 \%)$. Initial experiments showed that the seed of each species contained inhibitors which had to be removed by washing in running water for one week. The seed was then germinated on a Copenhagen table and the seedlings grown in seed trays for 3 weeks before transplanting to the pots containing added cobalt and copper.

Five specimens of each species were used for each concentration of each element. After two months of plant growth, the plant leaves and associated soils were analysed for copper and cobalt.

Leaf material was washed, dried at $100^{\circ} \mathrm{C}$, weighed and ashed at $500^{\circ} \mathrm{C}$. The ash was redissolved in $2 M$ hydrochloric acid and the solutions were analysed for copper and cobalt by atomic absorption spectrophotometry. Values were expressed as $\mu \mathrm{g} / \mathrm{g}$ (dry mass).

Soils were dried at $100^{\circ} \mathrm{C}$, and subsamples $(0.2 \mathrm{~g})$ were digested with $5 \mathrm{ml}$ of concentrated hydrochloric acid, taken to dryness and redissolved in $10 \mathrm{ml}$ of $2 M$ hydrochloric acid. Insoluble material was removed by centrifugation. The solutions were analysed for copper and cobalt as above.

\section{Results and discussion}

The experimental data are shown in Fig. 1. Each point represents the mean of 5 specimens. Logarithmic co-ordinates were used because of the wide range of values encountered.

Although concentrations of up to $10,000 \mu \mathrm{g} / \mathrm{g}(1 \%)$ were used for copper and cobalt in the soil, tolerances of each species varied very greatly. Haumaniastrum robertii tolerated cobalt concentrations of up to $4000 \mu \mathrm{g} / \mathrm{g}$ (to give $7200 \mu \mathrm{g} / \mathrm{g}$ in the dried leaves) and $8500 \mu \mathrm{g} / \mathrm{g}$ copper (only $28 \mu \mathrm{g} / \mathrm{g}$ in leaves). The closely-related Haumaniastrum katangense showed a much lower tolerance to both copper and cobalt. This species only tolerated cobalt levels of up to $600 \mu \mathrm{g} / \mathrm{g}$ and copper up to $1400 \mu \mathrm{g} / \mathrm{g}$ in the soil. Corresponding levels in dried leaves were $260 \mu \mathrm{g} / \mathrm{g}$ and $190 \mu \mathrm{g} / \mathrm{g}$ respectively. Tolerance levels for Aeolanthus biformifolius were $670 \mu \mathrm{g} / \mathrm{g}$ cobalt and $9000 \mu \mathrm{g} / \mathrm{g}$ copper in the soil. Corresponding values for dried leaves were $1900 \mu \mathrm{g} / \mathrm{g}$ cobalt and only $78 \mu \mathrm{g} / \mathrm{g}$ copper.

The curves shown in Fig. 1 have one common characteristic. They each have a discontinuity following a curve of low gradient at the lower concentration levels. Thereafter there is a sharp increase in gradient. This behaviour has been noted before ${ }^{1,6}$. It has been shown that elements essential to plant nutrition such as copper, have an approximately constant level in plants, irrespective of the amount in the soil. This is because the levels are internally rather than externally controlled. At higher copper concentrations in the soil, the mechanism breaks down and increased amounts of copper are taken up by the plant until the limit of tolerance is reached. This pattern of uptake is quite pronounced for 


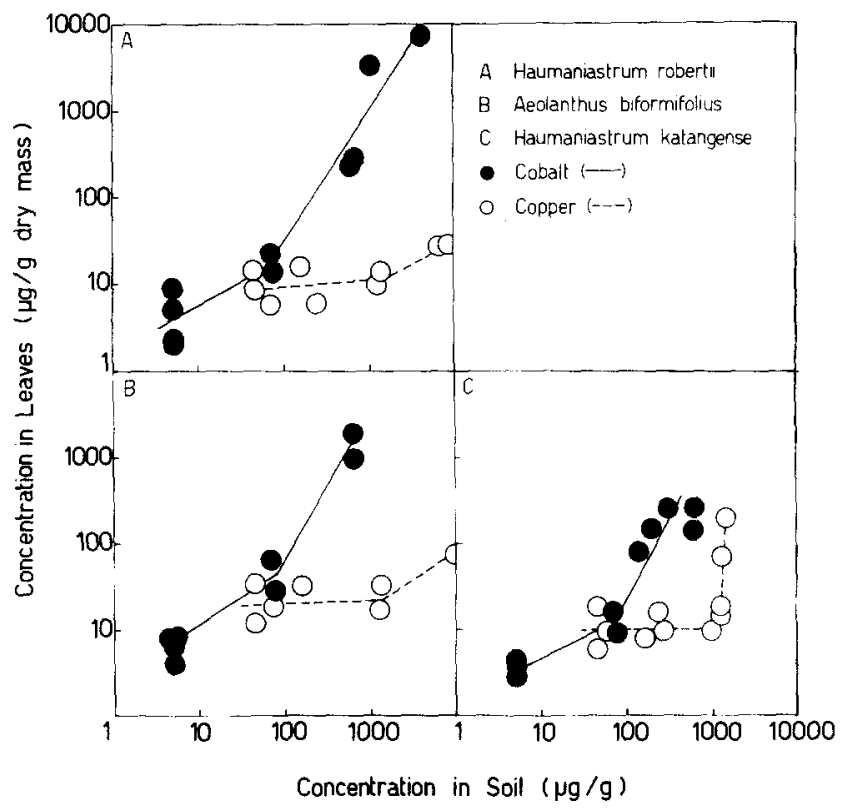

Fig. 1. Copper and cobalt concentrations in three plant species expressed as a function of the corresponding concentrations in the soil.

all three species. The discontinuities occur at about $1400 \mu \mathrm{g} / \mathrm{g}$ (soil level) for $\mathrm{A}$. biformifolius, $1200 \mu \mathrm{g} / \mathrm{g}$ for $H$. kantangense and $1700 \mu \mathrm{g} / \mathrm{g}$ for $A$. robertii. Although $A$. biformifolius is known to be a hyperaccumulator (>1000 g/g in dried vegetation) of copper ${ }^{5}$, it is surprising that the maximum value recorded here was only $78 \mu \mathrm{g} / \mathrm{g}$ instead of typical values of $2000 \mu \mathrm{g} / \mathrm{g}$ in basal leaves of specimens growing in the wild. There is however an explanation of this phenomenon. A. biformifolius forms corms at the end of the first season's growth. These corms typically contain about $2000 \mu \mathrm{g} / \mathrm{g}$ copper in January (at the beginning of the rainy season) rising to about $14,000 \mu \mathrm{g} / \mathrm{g}$ at the end of the rainy season in March $^{5}$. This accumulated store of copper is sufficient to give very elevated copper levels in leaves of the next season's growth. In our own experiments, the plants were raised from seed not corms and the copper levels in leaves were therefore correspondingly lower.

The curves for cobalt also how discontinuities at about $80 \mu \mathrm{g} / \mathrm{g}$. The curves for cobalt also show discontinuities at about $80 \mu \mathrm{g} / \mathrm{g}$ (in the soil) for $A$. biformifolius, $70 \mu \mathrm{g} / \mathrm{g}$ for $H$. katangense and $70 \mu \mathrm{g} / \mathrm{g}$ for $H$. robertii. The constancy of these values is as remarkable for cobalt as it is for copper. The gradient of the curves for cobalt at the lower concentrations (i.e. below the discontinuities) is greater for copper and implies a less pronounced exclusion mechanism for cobalt. The low-gradient curves below the discontinuities do however imply a certain degree of exclusion. Exclusion mechanisms are usually a means of either rejecting toxic heavy metals (such as lead) ${ }^{6}$ or else regulating an essential element to a constant level in the plant ${ }^{7}$. Although all three species are confined to mineralized ground, this does not necessarily indicate a physiological requirement for either cobalt or 
copper. Our pot trials have shown that all three species will grow on soils containing only traces of copper or cobalt. Nevertheless, losses are particularly severe in non-mineralized soils especially in the case of $H$. robertii. These losses were in most cases due to fungal infections and indicate a low tolerance of these plants to such attacks. This is to be expected since the normal substrates of all three species (and their leaves) have copper and/or cobalt levels sufficiently high to inhibit all fungal growth. This being the case, the species have a very low natural resistance to fungal attack. We have noted a similar behaviour during pot trials on nickel-accumulating Alyssum species. Although all three species would in fact grow in the absence of significant amounts of cobalt or copper, there were certain concentration ranges at which growth was optimal. These levels were $4000 \mu \mathrm{g} / \mathrm{g}(0.4 \%)$ cobalt or copper for $H$. robertii, $1000 \mu \mathrm{g} / \mathrm{g}(0.1 \%)$ cobalt or copper for $H$. kantangense, and $5000 \mu \mathrm{g} / \mathrm{g}$ copper for $A$. biformifolius. It is clear therefore that the distribution of these taxa is not influenced by a specific requirement for either element. It is much more likely that their peculiar distribution is a survival mechanism of plants unable to stand competition from other species. They have developed a strong tolerance to heavy metals which enables them to survive where their competitors cannot.

Another question to be considered is the value of these species for geobotanical or biogeochemical exploration studies. Certainly they are useful for geobotanical prospecting. They are reliable indicators of either cobalt or copper in the substrate. A. biformifolius is clearly a 'copper plant' though the same is not necessarily true for the two species of Haumaniastrum. Although $H$. katangense has already been designated as a "copper flower' ${ }^{3}$, it is likely that $H$. robertii with its surprisingly high tolerance to and accumulation of, cobalt ${ }^{2}$ is a "cobalt flower'. For a plant to be suitable for biogeochemical prospecting there should be a good relationship between the concentration of the element in the plant and the concentration level in the substrate. Correlation analysis of the data from our pot trials showed a non-significant relationship $(P>0.10)$ for copper in all three species but a very-highly-significant relationship $(P<0.001)$ for cobalt. The nonsignificant relationship for copper is because of the existence of two populations separated by the point when exclusion breaks down. Although there are probably two analogous populations for cobalt, the data points are sufficiently close to a single straight line for them to be considered to all intents and purposes as a single population. The cobalt content of all three species should therefore give some indication of the cobalt concentration in the substrate. Although theoretically of use in biogeochemical prospecting, it is unlikely that these species will ever be used for such a purpose because of their localized occurrence on ground obviously mineralized because of its stunted and sparse vegetation cover. Biogeochemical prospecting is extremely useful where the substrate is hard to reach because of an extensive humus cover or the existence of barriers such as siliceous hardpan, but in the mineralized areas of Shaba Province, Zaire, the soil is readily available and is covered with a low density of vegetation.

The most important question remaining unanswered is the nature of the copper and/or cobalt complexes in each of the three species. The mechanism whereby plants can tolerate high heavy metal concentrations in the substrate is of great importance in several fields. The extractions of copper and cobalt (especially cobalt) from their ores are processes involving a large amount of energy. Specialized plants such as the above are able to achieve this by a low energy process (sunlight) and if this could be emulated technologically, the benefits are obvious. 


\section{References}

1 Brooks, R. R. 1972 Geobotany and Biogeochemistry in Mineral Exploration, Harper Row, New York.

2 Brooks, R. R. 1977 Plant and Soil 48, 541-544.

3 Duvigneaud, P. 1958 Bull. Soc. R. Bot. Belg. 90, 127-286.

4 Howard-Williams, C. 1970 J. Ecol. 58, 745-763.

5 Malaisse, F. et al. 1978 Science 199, 887-888.

6 Nicolls, O. W. et al. 1965 Trans. Inst. Min. Metall. 74, 696-799.

7 Timperley, M. H. et al. 1970 J. Appl. Ecol. 7, 429439. 